\title{
Fermented, ultrasonicated, and dehydrated bovine colostrum: Changes in antimicrobial properties and immunoglobulin content
}

\author{
Elena Bartkiene, ${ }^{1,2,3 *}$ ๑ Vita Lele, ${ }^{1,2,3}$ Vytaute Sakiene, ${ }^{1,2,3}$ Paulina Zavistanaviciute, ${ }^{1,2,3}$ \\ Modestas Ruzauskas, ${ }^{3,4}$ @ Arunas Stankevicius, ${ }^{3,5}$ Juozas Grigas, ${ }^{3,4,5}$ Arnoldas Pautienius, ${ }^{3,4,5}$ \\ Jurga Bernatoniene, ${ }^{3,6}$ Valdas Jakstas, ${ }^{3}$ Daiva Zadeike, ${ }^{3,7}$ Pranas Viskelis, ${ }^{3,8}$ and Grazina Juodeikiene ${ }^{3,7}$ \\ ${ }_{1}^{1}$ Department of Food Safety and Quality, Lithuanian University of Health Sciences, Tilzes St. 18, LT-47181 Kaunas, Lithuania \\ ${ }^{2}$ Institute of Animal Rearing Technologies, Lithuanian University of Health Sciences, Tilzes St. 18, LT-47181 Kaunas, Lithuania \\ ${ }^{3}$ Institute of Pharmaceutical Technologies, Lithuanian University of Health Sciences, Sukilèliu pr. 13, LT-5016 Kaunas, Lithuania \\ ${ }^{4}$ Institute of Microbiology and Virology, Lithuanian University of Health Sciences, Tilzes St. 18, LT-47181 Kaunas, Lithuania \\ ${ }^{5}$ Department of Anatomy and Physiology, Institute of Microbiology and Virology, Lithuanian University of Health Sciences, Tilzes St. 18, \\ LT-47181 Kaunas, Lithuania \\ ${ }^{6}$ Department of Drug Technology and Social Pharmacy, Institute of Pharmaceutical Technologies, Lithuanian University of Health Sciences, \\ Sukilèlių pr. 13, LT-5016 Kaunas, Lithuania \\ ${ }^{7}$ Department of Food Science and Technology, Kaunas University of Technology, Radvilenu Rd. 19, LT-50254 Kaunas, Lithuania \\ ${ }^{8}$ Biochemistry and Technology Laboratory, Lithuanian Research Centre for Agriculture and Forestry, Institute of Horticulture, Kauno St. 30 , \\ LT-54333 Babtai, Lithuania
}

\section{ABSTRACT}

This study evaluated the influence of fermentation with Lactobacillus plantarum LUHS135 and Lactobacillus paracasei LUHS244, ultrasonication, and different methods of dehydration on the content of $\operatorname{IgG}, \operatorname{IgA}$, and $\mathrm{IgM}$ in bovine colostrum (BC), as well as the antimicrobial activity of the treated and fresh $\mathrm{BC}$ samples [fresh $=\mathrm{BC}$; freeze dried $=\mathrm{BC}_{\text {lyoph }}$; vacuum dried $\left(+45^{\circ} \mathrm{C}\right)=\mathrm{BC}_{\text {vacdried }} ; \mathrm{BC}$ fermented with LUHS135 = $\mathrm{BC}_{\mathrm{LUHS} 135}$; $\mathrm{BC}$ fermented with LUHS244 $=\mathrm{BC}_{\mathrm{LUHS244}}$; $\mathrm{BC}$ fermented with LUHS135 and freeze dried = $\mathrm{BC}_{\text {LUHS135lyoph }}$ BC fermented with LUHS244 and freeze dried $=\mathrm{BC}_{\mathrm{LUHS} 244 \text { lyoph }}$ BC fermented with LUHS135 and vacuum dried $=\mathrm{BC}_{\mathrm{LUHS} 135}$ vacdried $; \mathrm{BC}$ fermented with LUHS244 and vacuum dried $=\mathrm{BC}_{\mathrm{LUHS} 244}$ vacdried; $\mathrm{BC}$ ultrasonicated and freeze dried $=\mathrm{BC}_{\text {ultr lyoph }} ; \mathrm{BC}$ ultrasonicated and vacuum dried $=\mathrm{BC}_{\text {ultr vacdried }}$. The antimicrobial activity was assessed against Klebsiella pneumoniae, Salmonella enterica, Pseudomonas aeruginosa, Acinetobacter baumanni, Proteus mirabilis, methicillin-resistant Staphylococcus aureus, Enterococcus faecalis, Enterococcus faecium, Bacillus cereus, Streptococcus mutans, Enterobacter cloacae, Citrobacter freundii, Staphylococcus epidermis, Staphylococcus haemolyticus, and Pasteurella multocida using the agar

Received January 23, 2019.

Accepted October 29, 2019

*Corresponding author: elena.bartkiene@lsmuni.lt well diffusion method, as well as in liquid medium. In liquid medium analysis showed that the fermented $\mathrm{BC}$ samples had the broadest antimicrobial spectrum (of 15 tested pathogenic strains, $\mathrm{BC}_{\mathrm{LUHS} 135}$ vacdried and $\mathrm{BC}_{\text {LUHS135lyoph }}$ inhibited $13 ; \mathrm{BC}_{\mathrm{LUHS} 244}$ vacdried inhibited 12 ; and $\mathrm{BC}_{\mathrm{LUHS135}}, \mathrm{BC}_{\mathrm{LUHS} 244}$, and $\mathrm{BC}_{\mathrm{LUHS} 244 \text { lyoph }}$ inhibited 11). Based on the inhibition zones, $\mathrm{BC}_{\mathrm{LUHS} 135 \text { lyoph }}$ samples exhibited the broadest inhibition spectrum, inhibiting the growth of 12 of the 15 tested pathogenic strains). According to the lactic acid bacteria strain selected for $\mathrm{BC}$ fermentation, different properties of the $\mathrm{BC}$ will be obtained. To ensure a broad antimicrobial spectrum and high IgG content, fermentation with LUHS135 can be recommended (IgG concentration in $\mathrm{BC}_{\mathrm{LUHS135}}$ was retained), whereas fermentation with LUHS244 will provide a high IgM concentration (IgM concentration increased by 48.8 and $21.6 \%$ in $\mathrm{BC}_{\mathrm{LUHS} 244}$ and $\mathrm{BC}_{\mathrm{LUHS} 244 \text { yoph }}$ samples, respectively). However, $\operatorname{Ig} \mathrm{A}$ is very sensitive for fermentation, and further studies are needed to increase IgA stability in BC. Finally, fermented $\mathrm{BC}$ can be recommended as a food/beverage ingredient, providing safety, as well as improved functionality through displaying a broad spectrum of antimicrobial activities.

Key words: bovine colostrum, fermentation, immunoglobulin, drying, ultrasonication

\section{INTRODUCTION}

Functional and personalized characteristics are preferred today in the healthy food and beverage sectors. The food and beverage industries have many opportunities to prepare healthy and functional products 
that help people to improve their overall wellness by including new ingredients in the main food and beverage formulations. Nowadays, bovine colostrum (BC) is popular as a functional ingredient because it is associated with many health benefits (Saad et al., 2016; Chae et al., 2017). Bovine colostrum is well known as an antimicrobial, toxin neutralizer (Støy et al., 2014), and epithelial cell proliferation promoting agent (Rathe et al., 2014). Consequently, BC is a highly promising compound for functional food/beverages, as well as for nutraceutical preparation. Our previous study showed that fermented BC (up to 3\%) in combination with thyme essential oil (up to $0.2 \%$ ), and with mandarin or grapefruit essential oil (up to $0.2 \%$ ) for taste-masking, allowed obtaining good texture and high overall acceptability gummy candies containing desirable antimicrobials, and such antimicrobial candies could be a consumer-preferred form of nutraceuticals (Bartkiene et al., 2018c). However, the chemical composition of BC is very sensitive to technological treatment (McGrath et al., 2016), and the changes in chemical composition can lower the functionality of BC. Also, it is desirable that the ingredients used at an industrial scale will be convenient for usage and storage, and biological and chemical stability should be guaranteed.

We previously evaluated the influence of fermentation with Lactobacillus plantarum strain LUHS135 and Lactobacillus paracasei strain LUHS244, ultrasonication, and different methods of dehydration on the chemical composition of $\mathrm{BC}$, including fatty acid and free amino acid (FAA) profiles, as well as the content of microand macroelements (Bartkiene et al., 2018a). Also, the lactic acid bacteria (LAB) count, microbial contamination (aerobic mesophilic spore-forming bacteria; enterobacteria, including Escherichia coli; fungi/yeasts) as well as the concentrations of biogenic amines (BA) and nucleotide monophosphates (NM) in BC samples were analyzed (Bartkiene et al., 2018a). Although the minimum requirements for $\mathrm{BC}$ are $>50 \mathrm{~g} / \mathrm{L}$ of $\mathrm{IgG}$ and a total plate count of $<100,000 \mathrm{cfu} / \mathrm{mL}$, up to $60 \%$ of $\mathrm{BC}$ produced in the United States fails to meet these standards (Morrill et al., 2012). Ensuring BC has the minimum quality requirements is not easy because of the specific composition of $\mathrm{BC}$ (high protein content, as well as the presence of sensitive and antimicrobial compounds, such as immunoglobulins).

Only a few research investigations have been published about the influence of various preservation methods on the detailed chemical composition of BC (Ramya et al., 2016; Saalfeld et al., 2016; Denholm et al., 2017). However, we have shown that the use of ultrasonication and fermentation, as well as different methods of dehydration, can be promising technologies for $\mathrm{BC}$ treatment (Bartkiene et al., 2018a) because the use of the above- mentioned treatments significantly increased the total content of unsaturated, n-6, and n-9 fatty acids, as well as the FAA content in ultrasonicated BC samples. All of the treatments led to decreased microbial contamination in $\mathrm{BC}$ samples and lowered the presence of $\mathrm{BA}$ (cadaverine, histamine, tyramine). Conversely, the LAB count in all of the treated BC samples was $>6.00 \log _{10}$ $\mathrm{cfu} / \mathrm{mL}$. Moreover, it was found that the functionality of the $\mathrm{BC}$ could be greatly improved by fermentation of BC with LUHS135 strain, as it increased the NM concentration in BC samples (Bartkiene et al., 2018a). The NM are involved in many essential physiological processes. For this reason, dietary supplements of NM can be beneficial for humans under certain conditions (Domínguez-Álvarez et al., 2017). The European Food Safety Authority Panel on Dietetic Products, Nutrition and Allergies recommends supplementation of adapted milk products with up to $5 \mathrm{mg} / 100 \mathrm{kcal}$ of adenosine monophosphate, cytidine monophosphate, guanosine monophosphate, inosine monophosphate, and uridine monophosphate (EFSA NDA, 2014). Finally, it was concluded that a combination of fermentation, ultrasonication, and dehydration reduces the microbial contamination of $\mathrm{BC}$ and increases the NM concentration. Also, it was found that the technological LAB can reduce mycotoxin content in fermentable substrate (Bartkiene et al., 2018b,d), as well as in biological fluids (Ritieni et al., 2010). Nonetheless, more investigations are needed to evaluate the influence of these treatment methods on sensitive, biologically active compounds (e.g., immunoglobulins) in BC.

Immunoglobulins have potential as therapeutics in oncology, chronic inflammation, and cardiovascular, transplantation, and infectious diseases (Correia, 2010). For this reason, to ensure that they remain in $\mathrm{BC}$ after technological treatment would be very desirable because the inclusion of oral bovine immunoglobulins in the main food/beverage formulations may be a promising approach to support immune function in vulnerable groups, such as infants, children, elderly, and immunocompromised patients (Ulfman et al., 2018). The present study aimed to evaluate the influence of the treatments mentioned above (fermentation, ultrasound, and dehydration) on $\operatorname{IgG}$, IgA, and IgM contents in BC and, additionally, assess the antimicrobial activity of the treated $\mathrm{BC}$ samples against a range of pathogenic and opportunistic bacterial strains.

\section{MATERIALS AND METHODS}

\section{Materials}

The BC was obtained from "Linas Agro" agricultural company (Luksiai, Lithuania), within $2 \mathrm{~h}$ of calf deliv- 
ery. Samples were taken from 20 Lithuanian black-andwhite (Holstein) dairy cows in the winter (Bartkiene et al., 2018a). Lactobacillus plantarum LUHS135 and $L$. paracasei LUHS244 strains, for BC fermentation, were selected according to their good technological and antimicrobial properties (Bartkiene et al., 2018c). Before the experiment, LUHS135 and LUHS244 were stored at $-80^{\circ} \mathrm{C}$ in a Microbank system (Pro-Lab Diagnostics, Wirral, UK) and grown in de Man, Rogosa, and Sharpe (MRS) broth (CM 0359, Oxoid, Hampshire, UK) at $30^{\circ} \mathrm{C}$ for $48 \mathrm{~h}$ before use.

\section{Fermentation, Ultrasonication, and Dehydration of $B C$}

The LUHS135 and LUHS244 strains were grown in MRS medium (Biolife, Milan, Italy) at $30^{\circ} \mathrm{C}$. Two percent of the MRS solution (vol/vol), in which the strains were multiplied, was inoculated into fresh medium and propagated for $18 \mathrm{~h}$ at $30^{\circ} \mathrm{C}$. Further multiplied strains (average cell concentration $9.2 \log _{10} \mathrm{cfu} / \mathrm{mL}$ ) were used for BC fermentation. The LUHS135 and LUHS244 strains were added to the $\mathrm{BC}(3 \%, \mathrm{vol} / \mathrm{vol})$, followed by fermentation in a $\mathrm{CO}_{2}$ incubator (Memmert $\mathrm{GmbH}$ + Co. KG, Schwabach, Germany) for $24 \mathrm{~h}$ at $30^{\circ} \mathrm{C}$.

The BC was ultrasonicated at low frequency $(37 \mathrm{kHz}$, $160 \mathrm{~W}$ ) in a Proclean 3.0DSP apparatus (Ulsonix, Berlin, Germany). Each 20-g sample of BC was processed at $40^{\circ} \mathrm{C}$ for $20 \mathrm{~min}$, and each experiment was performed at least twice.

After fermentation with LUHS135 and LUHS244 strains, the BC samples were ultrasonicated, and as well as the nonfermented $\mathrm{BC}$ samples, were then dried: (1) freeze dried at $-40^{\circ} \mathrm{C}$ for $72 \mathrm{~h}$ (condenser temperature $-85^{\circ} \mathrm{C}$, pressure $2 \times 10^{-6} \mathrm{mPa}$; Sublimator $3 \times 4$ $\times 5$, Zirbus Technology, Bad Grund/Harz, Germany), and (2) vacuum dried (temperature $45 \pm 2.0^{\circ} \mathrm{C}$ and pressure $6 \times 10^{-3} \mathrm{mPa}$; XF020 vacuum dryer, France Etuves, Chelles, France).

In total, 11 samples were obtained: fresh $=\mathrm{BC}$; freeze dried $\left(-40^{\circ} \mathrm{C}\right)=\mathbf{B C}_{\text {lyoph }}$; vacuum dried $\left(+45^{\circ} \mathrm{C}\right)=$ $\mathbf{B C}_{\text {vacdried }}$; $\mathrm{BC}$ fermented with LUHS135 $=\mathbf{B C}_{\mathbf{L U H S 1 3 5}}$; $\mathrm{BC}$ fermented with LUHS244 = BC $_{\text {LUHS244 }} ; \mathrm{BC}$ fermented with LUHS135 and freeze dried $\left(-40^{\circ} \mathrm{C}\right)$ $=\mathbf{B C}_{\text {LUHS135 lyoph }} ; \mathrm{BC}$ fermented with LUHS244 and freeze dried $\left(-40^{\circ} \mathrm{C}\right)=\mathbf{B C}_{\text {LuHS244 lyoph }}$ BC fermented with LUHS135 and vacuum dried $\left(+45^{\circ} \mathrm{C}\right)=$ $\mathbf{B C}_{\text {LUHS135 vacdried; }} \mathrm{BC}$ fermented with LUHS244 and vacuum dried $\left(+45^{\circ} \mathrm{C}\right)=\mathbf{B C}_{\mathrm{LUHS244}}$ vacdried; $\mathrm{BC}$ ultrasonicated and freeze dried $\left(-40^{\circ} \mathrm{C}\right)=\mathbf{B C}_{\text {ultr lyoph }}$; $\mathrm{BC}$ ultrasonicated and vacuum dried $\left(+45^{\circ} \mathrm{C}\right)=$ $\mathrm{BC}_{\text {ultr vacdried. }}$.

\section{Determination of BC Antimicrobial Activities by the Agar Well Diffusion Method and in Liquid Medium}

All 11 BC samples were assessed for their antimicrobial activities against a variety of pathogenic and opportunistic bacterial strains (Klebsiella pneumoniae, Salmonella enterica 24 SPn06, Pseudomonas aeruginosa 17-331, Acinetobacter baumanni 17-380, Proteus mirabilis, methicillin-resistant Staphylococcus aureus (MRSA) M87fox, Enterococcus faecalis 86, Enterococcus faecium 103, Bacillus cereus 18 01, Streptococcus mutans, Enterobacter cloacae, Citrobacter freundii, Staphylococcus epidermis, Staphylococcus haemolyticus, and Pasteurella multocida) by the agar well diffusion method and in liquid medium.

For the agar well diffusion assay, suspensions of 0.5 McFarland standard of each pathogenic bacteria strain were inoculated onto the surface of cooled Mueller-Hinton agar (Oxoid, Basingstoke, UK) using sterile cotton swabs. Wells of $6 \mathrm{~mm}$ in diameter were punched in the agar and filled with $50 \mu \mathrm{L}$ of the $\mathrm{BC}$. The antimicrobial activities against the tested bacteria were established by measuring the inhibition zone diameters $(\mathrm{mm})$. The experiments were repeated 3 times, and the average of the inhibition zones was calculated.

To evaluate antimicrobial activity of $\mathrm{BC}$ in liquid medium, the $\mathrm{BC}$ was diluted 1:3 (vol/vol) with physiological solution. Then, to the $1 \mathrm{~mL}$ of the diluted BC, $10 \mu \mathrm{L}$ of the pathogenic and opportunistic bacterial strain, multiplied in a selective medium, was added and incubated at $35^{\circ} \mathrm{C}$ for $24 \mathrm{~h}$. After incubation, the viable pathogenic and opportunistic bacterial strains in $\mathrm{BC}$ were controlled, by plating them on selective medium. The results were interpreted as negative if the pathogens did not grow on selective medium, and positive if the pathogens grew on selective medium. Experiments were performed in triplicate.

\section{Determination of $\lg G, \operatorname{Ig} A$, and IgM Concentrations in BC Samples Using an ELISA Method}

For evaluation of $\operatorname{Ig} \mathrm{G}, \operatorname{Ig} \mathrm{A}$, and $\operatorname{IgM}$ concentrations, commercially available, 2-site ELISA kits (Abcam, Cambridge, UK) were used. The results were interpreted by spectrophotometric readings at $450 \mathrm{~nm}$ wavelength for all respective antibodies. Standards for antibody concentrations were prepared as instructed by the manufacturer, using serial dilutions. For quantitative analysis, 4-parameter logistic curves were constructed to calculate the antibody concentrations. For optimal quantification before the experiment, the 
samples were diluted $1 / 800,000$ for $\operatorname{IgG}, 1 / 20,000$ for $\operatorname{IgM}$, and $1 / 10,000$ for IgA testing.

\section{Statistical Analysis}

The results were expressed as the mean value of at least 3 measurements \pm standard deviation. To evaluate the effects of the different treatments on the antibody concentrations in $\mathrm{BC}$ samples, the data were analyzed by one-way ANOVA (SPSS version 22.0, IBM Corp., Armonk, NY). The results were deemed as statistically significant at $P \leq 0.05$.

\section{RESULTS AND DISCUSSION}

\section{Influence of Fermentation, Ultrasonication, and Dehydration on Antimicrobial Properties of BC}

Table 1 provides the inhibition zones of the fresh and treated $\mathrm{BC}$ samples against the pathogenic and opportunistic bacterial strains. The $\mathrm{BC}_{\mathrm{LUHS} 135}$ lyoph samples displayed the broadest inhibition spectrum, as they inhibited the growth of 12 out of the 15 tested pathogenic and opportunistic bacterial strains, including the highest inhibition zone against $K$. pneumoniae $(22.0 \pm 0.8$ $\mathrm{mm})$. Similar inhibition zones against $K$. pneumoniae were established by $\mathrm{BC}_{\mathrm{LUHS} 135}$ vacdried $(22.0 \pm 1.2 \mathrm{~mm})$ and $\mathrm{BC}_{\mathrm{LUHS} 244 \text { lyoph }}(23.0 \pm 1.3 \mathrm{~mm})$ samples, which also inhibited a broad spectrum of the tested pathogenic and opportunistic bacterial strains (both samples inhibited 10 out of the 15 tested strains). The $\mathrm{BC}_{\mathrm{LuHS} 135}$ and $\mathrm{BC}_{\mathrm{LUHS} 244}$ vacdried inhibited 9 out of the 15 tested pathogenic and opportunistic bacterial strains and the inhibition zones ranged from $16.0 \pm 1.3$ and $18.0 \pm 0.7$ $\mathrm{mm}\left(\mathrm{BC}_{\mathrm{LUHS135}}\right.$ and $\mathrm{BC}_{\mathrm{LUHS} 244 \text { vacdried }}$ against E. faecium 103 and $S$. epidermis, respectively) to $7.0 \pm 0.6$ and $9.0 \pm 0.4 \mathrm{~mm}\left(\mathrm{BC}_{\mathrm{LUHS} 135}\right.$ against $A$. baumanni $17-380$ and $\mathrm{BC}_{\mathrm{LUHS} 244 \text { vacdried }}$ against $A$. baumanni $17-380$ and MRSA M87fox), respectively. Five out of the 15 tested pathogenic and opportunistic bacterial strains were inhibited by $\mathrm{BC}_{\text {vacdried }}, \mathrm{BC}_{\text {ultr vacdried }}$, and $\mathrm{BC}_{\text {ultr lyoph }}$, and the ultrasonicated samples (vacuum dried and lyophilized) showed similar antimicrobial activities against the same pathogenic strains (K. pneumoniae, S. enterica 24 SPn06, MRSA M87fox, E. faecium 103, C. freundii).

Although the $\mathrm{BC}_{\text {vacdried }}$ samples did not demonstrate antimicrobial activities against E. faecium, they inhibited the growth of $B$. cereus 1801 (this strain was not inhibited by ultrasonicated BC samples). Fresh BC and $\mathrm{BC}_{\text {lyoph }}$ samples possessed the lowest inhibition properties, only inhibiting the growth of $2 / 15$ and $3 / 15$ of the tested pathogenic and opportunistic bacterial strains (fresh BC inhibited K. pneumoniae and MRSA M87fox, and $\mathrm{BC}_{\text {lyoph }}$ inhibited MRSA M87fox, E. faecium 103,

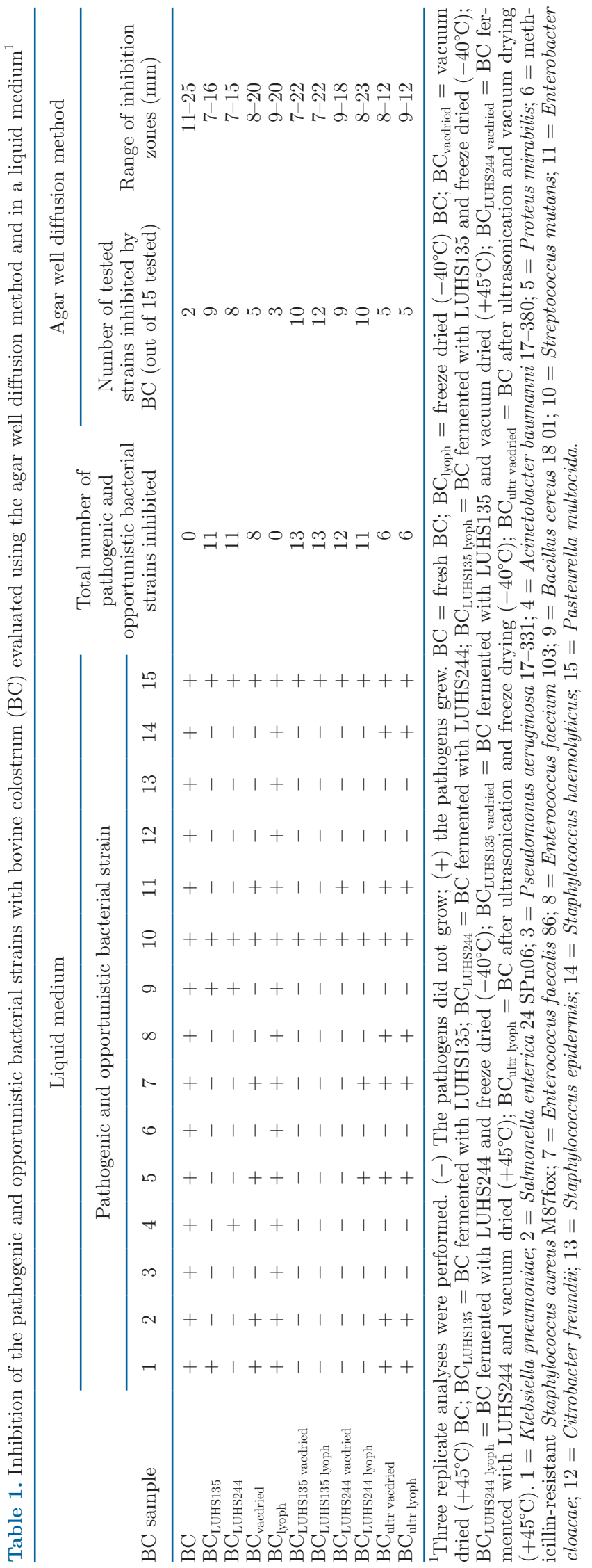


and P. multocida). The antimicrobial properties of the $\mathrm{BC}$ samples were affected by the fermentation with the different LAB strains: $\mathrm{BC}_{\mathrm{LUHS} 135}$ inhibited $S$. enterica 24 SPn06, A. baumanni 17-380, P. mirabilis, MRSA M87fox, E. faecalis 86, E. faecium 103, B. cereus 18 01, C. freundii, and S. epidermis, whereas $\mathrm{BC}_{\mathrm{LuHS} 244}$ inhibited S. enterica 24 SPn06, P. mirabilis, MRSA M87fox, E. faecalis 86, E. faecium 103, B. cereus 18 01, C. freundii, and P. aeruginosa 17-331.

Similar tendencies of the antimicrobial activity were observed in liquid medium (Table 1). Fresh BC and $\mathrm{BC}_{\text {lyoph }}$ samples did not inhibit the growth of the tested pathogenic and opportunistic bacterial strains. However, all of the other treated BC samples inhibited the growth of $P$. aeruginosa 17, MRSA M87fox, $C$. freundii, and $S$. epidermis. It should be mentioned that BC did not inhibit P. multocida in the liquid medium. The highest antimicrobial activity was displayed by the fermented $\mathrm{BC}$ samples (out of the 15 tested pathogenic and opportunistic bacterial strains, $\mathrm{BC}_{\mathrm{LUHS} 135}$ vacdried and $\mathrm{BC}_{\mathrm{LUHS135}}$ lyoph inhibited $13, \mathrm{BC}_{\mathrm{LUHS} 244}$ vacdried inhibited 12 , and $\mathrm{BC}_{\mathrm{LUHS} 135}, \mathrm{BC}_{\mathrm{LUHS} 244}$, and $\mathrm{BC}_{\mathrm{LUHS} 244 \text { lyoph }}$ inhibited 11). From the results obtained, it can be stated that the combination of $\mathrm{BC}$ with the selected $\mathrm{LAB}$ strains is very promising, as they can improve the BC antimicrobial activity.

It is known that the immunoglobulins found in BC bind to many human pathogens and allergens and can neutralize infection of human cells, as well as treat gastrointestinal inflammation (Ulfman et al., 2018). Also, passive oral administration of $\mathrm{BC}$ has been experimentally evaluated as a preventive or therapeutic modality for a variety of enteric infections (Tacket et al., 1988; Davidson et al., 1989; Tacket et al., 1992; Greenberg and Cello, 1996; Freedman et al., 1998; Savarino et al., 2017). Food formulations with BC can compensate or have a beneficial effect on health due to the addition of specific components if those components are lacking in the daily diet (Santini and Novellino, 2018). Furthermore, our results agree with Shahbazi et al. (2016) that the antimicrobial activity of ingredients can be increased by the combination of components with different antimicrobial properties, as well as by fermentation with LAB showing antimicrobial properties, and this technology might allow reduction of the dose of each compound. In addition, synergism of the different antimicrobials can be adapted in an attempt to prevent or delay the emergence of resistant populations of the pathogens (Mathur et al., 2017), and our results showed that after fermentation and ultrasonication, BC inhibited MRSA M87fox (established by both methods: inhibition zones and MIC). Bovine colostrum is a safe ingredient since there are no contraindications regarding high dose levels (Menchetti et al., 2016). Reducing the content of pathogenic bacteria is very important for public health because these microorganisms can cause diseases (Özogul and Hamed, 2018). For this reason, LAB are included in many technologies (as a technological or functional ingredient). However, LAB can decarboxylate FAA in fermentable substrates, which leads to BA formation. Conversely, BA can also be formed by foodborne pathogens, and our previous work showed that the use of LUHS135 and LUHS244 strains for $\mathrm{BC}$ fermentation reduced the concentrations of the $\mathrm{BA}$ and the pathogenic bacteria strains in BC (Bartkiene et al., 2018c). Lactic acid bacteria are associated with natural, healthy, as well as functional products, primarily because fermentation, as a natural preservation method, is more desirable by consumers, compared with chemical processes. Lactic acid bacteria produce a wide spectrum of antimicrobial compounds and are capable of inhibiting a variety of microorganisms in food, with a strong influence on safety.

\section{Influence of Fermentation, Ultrasonication, and Dehydration on $\lg G, \lg A$, and $\lg M$ Concentrations in BC}

Table 2 reveals the concentrations of $\operatorname{IgG}, \operatorname{IgA}$, and $\mathrm{IgM}$ in the $\mathrm{BC}$ samples. In comparing the IgG concentration between fresh and treated $\mathrm{BC}$ samples, the $\operatorname{IgG}$ concentration was retained in $\mathrm{BC}_{\mathrm{LuHS} 135}$ and $\mathrm{BC}_{\text {ultr vacdried. }}$ In $\mathrm{BC}_{\mathrm{LUHS} 244}$ and $\mathrm{BC}_{\mathrm{LUHS} 244 \text { vacdried }}$, the $\operatorname{IgG}$ concentration was 21.5 and $32.1 \%$, respectively, lower than that in fresh BC. In comparison, relatively higher IgG concentration decreases occurred in the fermented (with both strains) and lyophilized samples (41.8 and $38.2 \%$ in $\mathrm{BC}_{\mathrm{LUHS} 135}$ lyoph and $\mathrm{BC}_{\mathrm{LUHS} 244}$ lyoph , respectively). By combining the fermentation with LUHS135 strain and vacuum drying, the IgG loss in BC samples was $54.0 \%$, which was similar to that in the ultrasonicated and lyophilized sample $\left(51.3 \%\right.$ lower in $\mathrm{BC}_{\text {ultr lyoph }}$ compared with fresh $\mathrm{BC}$ ). The highest $\mathrm{IgG}$ losses were found in $\mathrm{BC}_{\text {lyoph }}$ and $\mathrm{BC}_{\text {vacdried, }}$, in which the $\operatorname{IgG}$ was reduced 4.2- and 3.0-fold, respectively, relative to the IgG content in fresh BC.

Different tendencies of the IgA concentration in $\mathrm{BC}$ samples were found. Among all the BC samples, the highest IgA concentration was established in $\mathrm{BC}_{\text {lyoph }}$ $(108.8 \pm 3.1 \mathrm{ng} / \mathrm{mL})$, whereas in fresh $\mathrm{BC}$, the concentration was $15.5 \%$ lower. When compared with fresh $\mathrm{BC}, \mathrm{BC}_{\text {ultr lyoph had }} 18.9 \%$ less $\operatorname{IgA}$, and in $\mathrm{BC}$ fermented with LUHS135 and LUHS244 strains, the $\operatorname{IgA}$ concentration was reduced by 51.5 and $96.1 \%$, respectively. The combination of ultrasonication and vacuum drying $\left(\mathrm{BC}_{\text {ultr vacdried }}\right)$ decreased the $\operatorname{IgA}$ concentration by 2.3 times relative to fresh $\mathrm{BC}$, but in vacuum-dried samples $\left(\mathrm{BC}_{\text {vacdried }}\right)$ this increased to 12.8 
times. These findings indicate that $\operatorname{IgA}$ is highly sensitive to the vacuum drying technique, as well as fermentation because, in fermented and lyophilized samples, very high losses of the IgA were detected compared with the $\mathrm{IgA}$ concentration in fresh $\mathrm{BC}(97.2$ and $96.4 \%$ lower in $\mathrm{BC}_{\mathrm{LUHS} 135 \text { lyoph }}$ and $\mathrm{BC}_{\mathrm{LUHS} 244 \text { lyoph }}$, respectively). The fermented and vacuum-dried samples had slightly more IgA than the fermented and lyophilized samples, but compared with the IgA concentration in fresh $\mathrm{BC}$, the amounts were $83.7 \%\left(\mathrm{BC}_{\mathrm{LUHS} 135 \text { vacdried }}\right)$ and $91.0 \%$ lower $\left(\mathrm{BC}_{\mathrm{LUHS} 244 \text { vacdried }}\right)$.

A comparison of the IgM concentrations among the BC samples showed that lyophilization, fermentation with LUHS244 strain, and their combination increased the $\operatorname{IgM}$ concentration by $51.2 \%\left(\mathrm{BC}_{\text {lyoph }}\right), 48.8 \%$ $\left(\mathrm{BC}_{\mathrm{LUHS} 244}\right)$, and $21.6 \%\left(\mathrm{BC}_{\mathrm{LUHS} 244}\right.$ lyoph $)$. Also, lower IgM contents were noticed in all $\mathrm{BC}$ fermented with LUHS135 compared with LUHS244 (58.3, 74.9, and $83.1 \%$ less in $\mathrm{BC}_{\mathrm{LUHS} 135}$ vs. $\mathrm{BC}_{\mathrm{LUHS} 244}, \mathrm{BC}_{\mathrm{LUHS} 135 \text { lyoph }}$ vs. $\mathrm{BC}_{\mathrm{LUHS} 244 \text { lyoph }}$, and $\mathrm{BC}_{\mathrm{LUHS} 135 \text { vacdried }} \mathrm{vs}$. $\mathrm{BC}_{\mathrm{LUHS} 244 \text { vacdried }}$, respectively). Vacuum drying of fresh $\mathrm{BC}$ also reduced the IgM level (7.8-fold). The $\mathrm{BC}_{\text {ultr lyoph }}$ had more than double the amount of IgM than in $\mathrm{BC}_{\text {ultr vacdried, }}$, but both had less than in fresh $\mathrm{BC}\left(74.4 \%\right.$ less in $\mathrm{BC}_{\text {ultr vacdried }}$ and $39.4 \%$ less in $\left.\mathrm{BC}_{\text {ultr lyoph }}\right)$.

Chemical preservation methods are not desirable for consumers and cannot preserve $\mathrm{BC}$ satisfactorily. For this reason, heating and freezing are the most preferred methods, and freeze drying is the more suitable technique because a higher concentration of active immunoglobulins can be saved (Borad and Singh, 2018). Also, spray drying, as well as high-pressure processing can be promising techniques to retain active immunoglobulins.
Nowadays, membrane processing is often employed to manipulate the composition of $\mathrm{BC}$ formulations, although new antimicrobial and functional properties for $\mathrm{BC}$ can be provided by fermentation with selected LAB strains. However, LAB can excrete proteolytic enzymes, which can lead to a highly proteinaceous substrate, as well as biodegradation of immunoglobulins. Biogenic amines can be formed from the FAA, but our previous investigation showed that fermentation, ultrasonication, and dehydration can be used to reduce the microbial contamination of $\mathrm{BC}$ (aerobic mesophilic spore-forming bacteria, enterobacteria, E. coli, and fungi/yeasts), which can also decarboxylate FAA, and in treated BC samples, lower concentrations of cadaverine, histamine, and tyramine were recorded compared with fresh BC (Bartkiene et al., 2018a). From another perspective, an increase in free essential, as well as nonessential AA in BC after fermentation and ultrasonication, or either technique, can be very promising, as it can lead to increased functionality of BC, as a food/ beverage component.

Also, oxidation of immunoglobulins can occur during the cell culture process, purification, formulation, and storage of the molecules. Studies reveal that oxidation of methionine residues not only results in loss of activity but also reduced stability of the molecule, potential immunogenicity, and decreased in vivo half-life (Teh et al., 1987; Lam et al., 1997; Hermeling et al., 2004; Chumsae et al., 2007; Liu et al., 2008).

Oxidation of immunoglobulins can take place on several different AA residues in the molecule, although methionine residues exposed to solvent tend to be the most susceptible (Kroon et al., 1992; Liu et al., 2008;

Table 2. Concentrations (ng/mL) of $\operatorname{IgG}$, IgA, and IgM in fresh, fermented, ultrasonicated, and dehydrated bovine colostrum (BC) samples ${ }^{1}$

\begin{tabular}{lrrr}
\hline BC sample & \multicolumn{1}{c}{ IgG } & \multicolumn{1}{c}{ IgA } & \multicolumn{1}{c}{ IgM } \\
\hline $\mathrm{BC}$ & $155.7 \pm 2.3^{\mathrm{h}}$ & $108.8 \pm 3.1^{\mathrm{h}}$ & $181.1 \pm 3.1^{\mathrm{h}}$ \\
$\mathrm{BC}_{\mathrm{LUHS135}}$ & $157.2 \pm 1.9^{\mathrm{h}}$ & $44.6 \pm 2.4^{\mathrm{e}}$ & $74.4 \pm 2.4^{\mathrm{e}}$ \\
$\mathrm{BC}_{\mathrm{LUHS244}}$ & $122.3 \pm 3.0^{\mathrm{g}}$ & $3.6 \pm 0.5^{\mathrm{a}}$ & $178.2 \pm 3.9^{\mathrm{h}}$ \\
$\mathrm{BC}_{\text {lyoph }}$ & $36.7 \pm 2.1^{\mathrm{a}}$ & $91.9 \pm 1.6^{\mathrm{g}}$ & $119.8 \pm 3.6^{\mathrm{f}}$ \\
$\mathrm{BC}_{\text {vacdried }}$ & $52.3 \pm 2.7^{\mathrm{b}}$ & $7.2 \pm 1.1^{\mathrm{b}}$ & $15.4 \pm 1.0^{\mathrm{b}}$ \\
$\mathrm{BC}_{\mathrm{LUHS135} \text { lyoph }}$ & $90.6 \pm 3.4^{\mathrm{d}}$ & $2.6 \pm 0.4^{\mathrm{a}}$ & $36.6 \pm 1.7^{\mathrm{d}}$ \\
$\mathrm{BC}_{\mathrm{LUHS} 244 \text { lyoph }}$ & $96.3 \pm 2.9^{\mathrm{e}}$ & $3.3 \pm 0.5^{\mathrm{a}}$ & $145.6 \pm 3.8^{\mathrm{g}}$ \\
$\mathrm{BC}_{\mathrm{LUHS135} \text { vacdried }}$ & $71.6 \pm 1.7^{\mathrm{c}}$ & $15.0 \pm 1.3^{\mathrm{c}}$ & $5.0 \pm 0.6^{\mathrm{a}}$ \\
$\mathrm{BC}_{\mathrm{LUHS244} \text { vacdried }}^{\mathrm{c}}$ & $105.7 \pm 3.5^{\mathrm{f}}$ & $8.3 \pm 0.9^{\mathrm{b}}$ & $29.6 \pm 1.4^{\mathrm{c}}$ \\
$\mathrm{BC}_{\text {ultr vacdried }}$ & $154.1 \pm 3.1^{\mathrm{h}}$ & $39.4 \pm 1.2^{\mathrm{d}}$ & $30.7 \pm 1.6^{\mathrm{c}}$ \\
$\mathrm{BC}_{\text {ultr lyoph }}$ & $75.8 \pm 2.7^{\mathrm{c}}$ & $74.5 \pm 2.8^{\mathrm{f}}$ & $72.6 \pm 2.0^{\mathrm{e}}$ \\
\hline
\end{tabular}

${ }^{\mathrm{a}-\mathrm{h}}$ Mean values with different superscripts are significantly different $(P \leq 0.05)$.

${ }^{1}$ Values are mean $\pm \mathrm{SD}$ of 3 replicate analyses $(\mathrm{n}=3)$. $\mathrm{BC}=$ fresh $\mathrm{BC} ; \mathrm{BC}_{\text {lyoph }}=$ freeze dried $\left(-40^{\circ} \mathrm{C}\right) \mathrm{BC}$; $\mathrm{BC}_{\text {vacdried }}=$ vacuum dried $\left(+45^{\circ} \mathrm{C}\right) \mathrm{BC} ; \mathrm{BC}_{\mathrm{LUHS} 135}=\mathrm{BC}$ fermented with LUHS135; $\mathrm{BC}_{\mathrm{LUHS} 244}=\mathrm{BC}$ fermented with LUHS244; $\mathrm{BC}_{\mathrm{LUHS135} \text { lyoph }}=\mathrm{BC}$ fermented with LUHS135 and freeze dried $\left(-40^{\circ} \mathrm{C}\right) ; \mathrm{BC}_{\mathrm{LUHS} 244 \text { lyoph }}=$ $\mathrm{BC}$ fermented with LUHS244 and freeze dried $\left(-40^{\circ} \mathrm{C}\right) ; \mathrm{BC}_{\mathrm{LUHS} 135}$ vacdried $=\mathrm{BC}$ fermented with LUHS135 and vacuum dried $\left(+45^{\circ} \mathrm{C}\right) ; \mathrm{BC}_{\mathrm{LUHS} 244 \text { vacdried }}=\mathrm{BC}$ fermented with LUHS244 and vacuum dried $\left(+45^{\circ} \mathrm{C}\right) ; \mathrm{BC}_{\text {ultr lyoph }}$ $=\mathrm{BC}$ after ultrasonication and freeze drying $\left(-40^{\circ} \mathrm{C}\right) ; \mathrm{BC}_{\mathrm{ultr}}$ vacdried $=\mathrm{BC}$ after ultrasonication and vacuum drying $\left(+45^{\circ} \mathrm{C}\right)$. 
Table 3. Correlations between immunoglobulin concentration in bovine colostrum samples and their antimicrobial activity assessed using the agar diffusion method

\begin{tabular}{lrrr}
\hline Pathogenic strain & IgG & \multicolumn{1}{c}{ IgA } & \multicolumn{1}{c}{$\operatorname{IgM}$} \\
\hline Klebsiella pneumoniae & -0.3174 & -0.3185 & -0.3147 \\
Salmonella enterica 24 SPn06 & 0.3696 & 0.0849 & 0.2642 \\
Pseudomonas aeruginosa 17-331 & -0.1070 & -0.7258 & 0.0035 \\
Acinetobacter baumanni 17-380 & -0.0049 & -0.5654 & -0.3165 \\
Proteus mirabilis & 0.4833 & -0.0826 & 0.2318 \\
Methicillin-resistant Staphylococcus aureus M87fox & -0.1581 & 0.6765 & 0.3363 \\
Enterococcus faecalis 86 & 0.3888 & -0.3012 & 0.5154 \\
Enterococcus faecium 103 & 0.1682 & -0.7132 & -0.4182 \\
Bacillus cereus & -0.0361 & -0.5130 & 0.0784 \\
Streptococcus mutans & -0.0052 & -0.3838 & 0.0305 \\
Enterobacter cloacae & -0.2228 & -0.5577 & -0.3910 \\
Citrobacter freundii & -0.1838 & -0.3916 & -0.3675 \\
Staphylococcus epidermis & 0.2752 & -0.2573 & 0.0321 \\
Staphylococcus haemolyticus & - & - & - \\
Pasteurella multocida & -0.3905 & -0.2470 & -0.3329 \\
\hline
\end{tabular}

Bertolotti-Ciarlet et al., 2009; Pan et al., 2009). We previously showed that the lowest concentration of free methionine was in freeze-dried $\mathrm{BC}$ samples, and ultrasonication increased the content of methionine (the highest level of methionine was established in ultrasonicated and vacuum-dried BC; Bartkiene et al., 2018a). Increasing the methionine can be desirable, as this AA has an essential role in protein synthesis (Xue et al., 2015).

Variations in the influence on various immunoglobulins by fermentation, ultrasonication, and different drying methods can be observed, but to increase the functionality and antimicrobial properties of $\mathrm{BC}$, fermentation with LUHS135 and LUHS244 can be recommended. According to the selected strain, different characteristics of the $\mathrm{BC}$ will be obtained. Correlations between immunoglobulin concentration in BC samples and their antimicrobial activity assessed by the agar diffusion method are presented in Table 3. Weak negative correlations between $K$. pneumoniae and all the tested immunoglobulins, between A. baumanni 17-380 and $\operatorname{IgM}$, between $E$. faecalis 86 and $\operatorname{IgA}$, between $S$. mutans and $\operatorname{IgA}$, between E. cloacae and IgM, between $C$. freundii and $\operatorname{IgA}$, as well as IgM, and between $P$. multocida and IgG, as well as IgM were found. Moderate negative correlations between $A$. baumanni $17-380$ and $\operatorname{IgA}$, between E. faecium 103 and $\operatorname{IgM}$, between $B$. cereus and IgA, and between E. cloacae and IgA were established. Also, negative strong correlations between A. baumanni $17-380$ and $\operatorname{IgA}$, as well as between $E$. faecium 103 and IgA were found. These results showed that immunoglobulins are not responsible for the inhibition of the above mentioned pathogenic strains. However, weak positive correlations between $\operatorname{IgG}$ and S. enterica 24 SPn06, as well as E. faecalis 86 were found, and moderate positive correlations between IgA and MRSA M87fox, as well as between IgM and E. faecalis 86 were established. According to Polonelli et al. (2017), the antimicrobial, antiviral, antitumor, and immunomodulatory activities are exerted through different mechanisms of action, and the immunoglobulin peptides are active as antibodies, independently from their specificity and isotype. The antimicrobial activity of BC can also depend on the concentration used. Chae et al. (2017) noted that increasing the BC concentration reduced E. coli bacterial adherence to the cells, and showed direct antibacterial activity.

To ensure a broad antimicrobial spectrum and high IgG content, fermentation with LUHS135 should be chosen, whereas fermentation with LUHS244 will provide a high IgM concentration. It should be mentioned that IgA is very sensitive to fermentation and further studies should aim to increase IgA stability in BC during the technological processes.

\section{CONCLUSIONS}

It was established that the broadest antimicrobial spectrum was displayed by the fermented $\mathrm{BC}$ samples (out of 15 tested pathogens, $\mathrm{BC}_{\mathrm{LUHS} 135}$ vacdried and $\mathrm{BC}_{\mathrm{LUHS} 135}$ lyoph inhibited $13, \mathrm{BC}_{\mathrm{LUHS} 244}$ vacdried inhibited 12 , and $\mathrm{BC}_{\mathrm{LUHS} 135}, \mathrm{BC}_{\mathrm{LUHS} 244}$, and $\mathrm{BC}_{\mathrm{LUHS} 244 \text { lyoph }}$ inhibited 11), indicating fermentation of $\mathrm{BC}$ with selected LAB strains can improve the functionality of this ingredient. The properties of the $\mathrm{BC}$ depend on the $\mathrm{LAB}$ strain selected for $\mathrm{BC}$ fermentation. To ensure a broad antimicrobial activity and high IgG content of BC, fermentation with LUHS135 strain can be recommended. To provide a high IgM concentration, fermentation with LUHS244 should be selected (IgM concentration increased by 48.8 and $21.6 \%$ in $\mathrm{BC}_{\mathrm{LUHS} 244}$

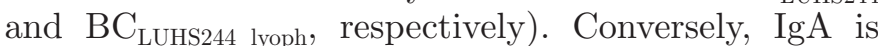
very sensitive to fermentation, and further studies are needed to increase IgA stability in BC. Finally, the fer- 
mentation of BC with LUHS135 and LUHS244 strains is a promising technology for $\mathrm{BC}$, as a food/beverage ingredient due to its safety and functionality, which includes providing a broad spectrum of antimicrobial activities, as well as active immunoglobulins.

\section{ACKNOWLEDGMENTS}

This research is funded by the European Regional Development Fund according to the supported activity 'Research Projects Implemented by World-class Researcher Groups' under Measure No. 01.2.2-LMT$\mathrm{K}-718$. The authors have no conflict of interest to declare.

\section{REFERENCES}

Bartkiene, E., V. Bartkevics, L. E. Ikkere, I. Pugajeva, P. Zavistanaviciute, V. Lele, M. Ruzauskas, J. Bernatoniene, V. Jakstas, D. Klupsaite, D. Zadeike, P. Viskelis, and G. Juodeikiene. 2018a. The effects of ultrasonication, fermentation with Lactobacillus sp., and dehydration on the chemical composition and microbial contamination of bovine colostrum. J. Dairy Sci. 101:6787-6798. https://doi.org/10.3168/jds.2018-14692.

Bartkiene, E., V. Bartkevics, V. Krungleviciute, G. Juodeikiene, D. Zadeike, J. Damasius, V. Baliukoniene, B. Bakutis, A. Santini, and D. Cizeikiene. 2018b. Application of hydrolases and probiotic Pediococcus acidilactici BaltBiol.01 strain for cereal by-product conversion to bioproduct for food/feed. Int. J. Food Sci. Nutr. 69:165-175. https://doi.org/10.1080/09637486.2017.1344828.

Bartkiene, E., M. Ruzauskas, V. Lele, P. Zavistanaviciute, J. Bernatoniene, V. Jakstas, L. Ivanauskas, D. Zadeike, D. Klupsaite, P. Viskelis, J. Bendoraitiene, V. Navikaite-Snipaitiene, and G. Juodeikiene. 2018c. Development of antimicrobial gummy candies with addition of bovine colostrum, essential oils and probiotics. Int. J. Food Sci. Technol. 53:1227-1235. https://doi.org/10.1111/ ijfs. 13701.

Bartkiene, E., P. Zavistanaviciute, V. Lele, M. Ruzauskas, V. Bartkevics, J. Bernatoniene, P. Gallo, G. C. Tenore, and A. Santini. 2018d. Lactobacillus plantarum LUHS135 and paracasei LUHS244 as functional starter cultures for the food fermentation industry: Characterisation, mycotoxin-reducing properties, optimisation of biomass growth and sustainable encapsulation by using dairy byproducts. Lebensm. Wiss. Technol. 93:649-658. https://doi.org/10 .1016/j.lwt.2018.04.017.

Bertolotti-Ciarlet, A., W. Wang, R. Lownes, P. Pristatsky, Y. Fang, T. McKelvey, Y. Li, Y. Li, J. Drummond, T. Prueksaritanont, and J. Vlasak. 2009. Impact of methionine oxidation on the binding of human IgG1 to FcRn and Fcy receptors. Mol. Immunol. 46:18781882. https://doi.org/10.1016/j.molimm.2009.02.002.

Borad, S. G., and A. K. Singh. 2018. Colostrum immunoglobulins: Processing, preservation and application aspects. Int. Dairy J. 85:201-210. https://doi.org/10.1016/j.idairyj.2018.05.016.

Chae, A., A. Aitchison, A. S. Day, and J. I. Keenan. 2017. Bovine colostrum demonstrates anti-inflammatory and antibacterial activity in in vitro models of intestinal inflammation and infection. J. Funct. Foods 28:293-298. https://doi.org/10.1016/j.jff.2016.11 .016 .

Chumsae, C., G. Gaza-Bulseco, J. Sun, and H. Liu. 2007. Comparison of methionine oxidation in thermal stability and chemically stressed samples of a fully human monoclonal antibody. J. Chromatogr. B Analyt. Technol. Biomed. Life Sci. 850:285-294. https:/ /doi.org/10.1016/j.jchromb.2006.11.050.

Correia, I. R. 2010. Stability of IgG isotypes in serum. MAbs 2:221232. https://doi.org/10.4161/mabs.2.3.11788.
Davidson, G. P., E. Daniels, H. Nunan, A. G. Moore, P. B. D. Whyte, K. Franklin, P. I. McCloud, and D. J. Moore. 1989. Passive immunisation of children with bovine colostrum containing antibodies to human rotavirus. Lancet 2:709-712. https://doi.org/10 .1016/S0140-6736(89)90771-X.

Denholm, K. S., J. C. Hunnam, E. L. Cuttance, and S. McDougall. 2017. Influence of preservation methods on the quality of colostrum sourced from New Zealand dairy farms. N. Z. Vet. J. 65:264269. https://doi.org/10.1080/00480169.2017.1342574.

Domínguez-Álvarez, J., M. Mateos-Vivas, E. Rodríguez-Gonzalo, D. García-Gómez, M. Bustamante-Rangel, M.-M. Delgado Zamarreño, and R. Carabias-Martínez. 2017. Determination of nucleosides and nucleotides in food samples by using liquid chromatography and capillary electrophoresis. Trends Analyt. Chem. 92:12-31. https://doi.org/10.1016/j.trac.2017.04.005.

EFSA NDA. 2014. EFSA Panel on Dietetic Products, Nutrition and Allergies. Scientific opinion on the essential composition of infant and follow-on formulae. EFSA J. 12:3760. https://doi.org/10 $.2903 /$ j.efsa.2014.3760.

Freedman, D. J., C. O. Tacket, A. Delehanty, D. R. Maneval, J. Nataro, and J. H. Crabb. 1998. Milk immunoglobulin with specific activity against purified colonization factor antigens can protect against oral challenge with enterotoxigenic Escherichia coli. J. Infect. Dis. 177:662-667. https://doi.org/10.1086/514227.

Greenberg, P. D., and J. P. Cello. 1996. Treatment of severe diarrhea caused by Cryptosporidium parvum with oral bovine immunoglobulin concentrate in patients with AIDS. J. Acquir. Immune Defic. Syndr. Hum. Retrovirol. 13:348-354. https://doi.org/10.1097/ 00042560-199612010-00008.

Hermeling, S., D. J. A. Crommelin, H. Schellekens, and W. Jiskoot. 2004. Structure-immunogenicity relationships of therapeutic proteins. Pharm. Res. 21:897-903. https://doi.org/10.1023/B:PHAM .0000029275.41323.a6.

Kroon, D. J., A. Baldwin-Ferro, and P. Lalan. 1992. Identification of sites of degradation in a therapeutic monoclonal antibody by peptide mapping. Pharm. Res. 9:1386-1393. https://doi.org/10.1023/ A:1015894409623.

Lam, X. M., J. Y. Yang, and J. L. Cleland. 1997. Antioxidants for prevention of methionine oxidation in recombinant monoclonal antibody HER2. J. Pharm. Sci. 86:1250-1255. https://doi.org/10 $.1021 / \mathrm{js} 970143 \mathrm{~s}$.

Liu, D., D. Ren, H. Huang, J. Dankberg, R. Rosenfeld, M. J. Cocco, L. Li, D. N. Brems, and R. L. Remmele Jr. 2008. Structure and stability changes of human IgG1 Fc as a consequence of methionine oxidation. Biochemistry 47:5088-5100. https://doi.org/10.1021/ bi702238b.

Mathur, H., D. Field, M. C. Rea, P. D. Cotter, C. Hill, and R. P. Ross. 2017. Bacteriocin-antimicrobial synergy: A medical and food perspective. Front. Microbiol. 8:1205. https://doi.org/10.3389/fmicb .2017 .01205 .

McGrath, B. A., P. F. Fox, P. L. H. McSweeney, and A. L. Kelly. 2016. Composition and properties of bovine colostrum: A review. Dairy Sci. Technol. 96:133-158. https://doi.org/10.1007/s13594 -015-0258-x.

Menchetti, L., G. Traina, G. Tomasello, P. Casagrande-Proietti, L. Leonardi, O. Barbato, and G. Brecchia. 2016. Potential benefits of colostrum in gastrointestinal diseases. Front. Biosci. 8:331-351. https://doi.org/10.2741/s467.

Morrill, K. M., E. Conrad, A. Lago, J. Campbell, J. Quigley, and H. Tyler. 2012. Nationwide evaluation of quality and composition of colostrum on dairy farms in the United States. J. Dairy Sci. 95:3997-4005. https://doi.org/10.3168/jds.2011-5174.

Özogul, F., and I. Hamed. 2018. The importance of lactic acid bacteria for the prevention of bacterial growth and their biogenic amines formation: A review. Crit. Rev. Food Sci. Nutr. 58:1660-1670. https://doi.org/10.1080/10408398.2016.1277972.

Pan, H., K. Chen, L. Chu, F. Kinderman, I. Apostol, and G. Huang. 2009. Methionine oxidation in human IgG2 Fc decreases binding affinities to protein A and FcRn. Protein Sci. 18:424-433. https: /doi.org/10.1002/pro.45 
Polonelli, L., T. Ciociola, M. Sperindè, L. Giovati, T. D'Adda, S. Galati, L. R. Travassos, W. Magliani, and S. Conti. 2017. Fungicidal activity of peptides encoded by immunoglobulin genes. Sci. Rep. 7:10896. https://doi.org/10.1038/s41598-017-11396-6.

Ramya, S. B., D. Ramasamy, and V. Dhineshkumar. 2016. Effects of refrigeration, deep freezing-spray drying and pasteurization on IgG bovine colostrum preservation. Int. J. Dairy Process. Res. 3:35-37. https://doi.org/10.19070/2379-1578-160010.

Rathe, M., K. Müller, P. T. Sangild, and S. Husby. 2014. Clinical applications of bovine colostrum therapy: A systematic review. Nutr. Rev. 72:237-254. https://doi.org/10.1111/nure.12089.

Ritieni, A., A. Santini, M. Mussap, R. Ferracane, P. Bosco, D. Gazzolo, and F. Galvano. 2010. Simultaneous determination of mycotoxins in biological fluids by LC-MS/MS. Front. Biosci. E2:151-158. https://doi.org/10.2741/e77.

Saad, K., M. G. M. Abo-Elela, K. A. A. El-Baseer, A. E. Ahmed, F.-A. Ahmad, M. S. K. Tawfeek, A. A. El-Houfey, M. D. AboulKhair, A. M. Abdel-Salam, A. Abo-elgheit, H. Qubaisy, A. M. Ali, and E. Abdel-Mawgoud. 2016. Effects of bovine colostrum on recurrent respiratory tract infections and diarrhea in children. Medicine (Baltimore) 95:e4560. https://doi.org/10.1097/MD.0000000000004560.

Saalfeld, M. H., D. I. B. Pereira, J. S. S. Valente, J. L. Borchardt, C. F. Weissheimer, M. A. Gularte, and F. P. L. Leite. 2016. Effect of anaerobic bovine colostrum fermentation on bacteria growth inhibition. Cienc. Rural 46:2152-2157. https://doi.org/10.1590/0103 $-8478 \mathrm{cr} 20160393$.

Santini, A., and E. Novellino. 2018. Nutraceuticals - Shedding light on the grey area between pharmaceuticals and food. Expert Rev. Clin. Pharmacol. 11:545-547. https://doi.org/10.1080/17512433 2018.1464911.

Savarino, S. J., R. McKenzie, D. R. Tribble, C. K. Porter, A. O'Dowd, J. A. Cantrell, A. A. Sincock, S. T. Poole, B. DeNearing, C. M. Woods, H. Kim, S. L. Grahek, C. Brinkley, J. H. Crabb, and A. L. Bourgeois. 2017. Prophylactic efficacy of hyperimmune bovine colostral antiadhesin antibodies against enterotoxigenic Escherichia coli diarrhea: A randomized, double-blind, placebo-controlled, phase 1 trial. J. Infect. Dis. 216:7-13. https://doi.org/10.1093/ infdis/jix144.

Shahbazi, Y., N. Shavisi, and E. Mohebi. 2016. Effects of Ziziphora clinopodioides essential oil and nisin, both separately and in combination, to extend shelf life and control Escherichia coli O157:H7 and Staphylococcus aureus in raw beef patty during refrigerated storage. J. Food Saf. 36:227-236. https://doi.org/10.1111/jfs .12235 .

Støy, A. C. F., P. M. H. Heegaard, T. Thymann, M. Bjerre, K. Skovgaard, M. Boye, B. Stoll, M. Schmidt, B. B. Jensen, and P. T. Sangild. 2014. Bovine colostrum improves intestinal function following formula-induced gut inflammation in preterm pigs. Clin. Nutr. 33:322-329. https://doi.org/10.1016/j.clnu.2013.05.013.

Tacket, C. O., S. B. Binion, E. Bostwick, G. Losonsky, M. J. Roy, and R. Edelman. 1992. Efficacy of bovine milk immunoglobulin concentrate in preventing illness after Shigella flexneri challenge. Am. J. Trop. Med. Hyg. 47:276-283. https://doi.org/10.4269/ajtmh .1992.47.276.

Tacket, C. O., G. Losonsky, H. Link, Y. Hoang, P. Guesry, H. Hilpert, and M. M. Levine. 1988. Protection by milk immunoglobulin concentrate against oral challenge with enterotoxigenic Escherichia coli. N. Engl. J. Med. 318:1240-1243. https://doi.org/10.1056/ NEJM198805123181904.

Teh, L. C., L. J. Murphy, N. L. Huq, A. S. Surus, H. G. Friesen, L. Lazarus, and G. E. Chapman. 1987. Methionine oxidation in human growth hormone and human chorionic somatomammotropin. Effects on receptor binding and biological activities. J. Biol Chem. 262:6472-6477. https://pdfs.semanticscholar.org/c08d/ 830a1bf1a624ae5ff8fb0870dea1e50d7610.pdf.

Ulfman, L. H., J. H. W. Leusen, H. F. J. Savelkoul, J. O. Warner, and R. J. J. van Neerven. 2018. Effects of bovine immunoglobulins on immune function, allergy, and infection. Front. Nutr. 5:52. https:/ /doi.org/10.3389/fnut.2018.00052.

Xue, M., J. Long, Q. Jiang, M. Wang, S. Chen, Q. Pang, and Y He. 2015. Distinct patterns of the histone marks associated with recruitment of the methionine chain-elongation pathway from leucine biosynthesis. J. Exp. Bot. 66:805-812. https://doi.org/10 $.1093 / \mathrm{jxb} / \mathrm{eru} 440$.

\section{ORCIDS}

Elena Bartkiene (ํ) https://orcid.org/0000-0003-3706-1280

Modestas Ruzauskas () https://orcid.org/0000-0002-1040-0249 